\title{
A Study on internet addiction among teenagers in selangor state of malaysia
}

\author{
Raja Kumar Murugesan ${ }^{1, *}$, Siti Khadijah Binti Mohd Hamzaht ${ }^{2}$, and Supriyanto ${ }^{3}$ \\ ${ }^{1}$ Taylor's University, Malaysia \\ ${ }^{2}$ International University of Malaysia Wales, Malaysia \\ ${ }^{3}$ University of Sultan Ageng Tirtayasa, Indonesia
}

\begin{abstract}
Internet addiction is becoming a growing phenomenon across the world due to the tendency of Internet overuse for varied reasons. The objective of this study is to identify the extent of Internet use and level of addiction among teenagers with the age ranging from 13 to 17 years old. This also include the risk factor and impact to their social life. The sample data were taken from several schools covering 500 students from the state of Selangor in Malaysia. The survey was done using an instrument from Internet Addiction Test (IAT) developed by Dr. Kimberly Young. This test had been modified to meet the requirements of the youngster's mind-set in Malaysia. Demographics factors such as age, gender and race were examined apart from family and personal factors. The results of the study and Chi-square test summarizes that the level of internet addiction among teenagers in Selangor is $p=0.161$ and tends to be minimal. We need to be aware of the level of Internet usage by teenagers so that measures could be made in place to deter or mitigate Internet addiction.
\end{abstract}

\section{Introduction}

The Internet since its inception for public use in the late 1980s has grown exponentially connecting people globally turning the world in to a global village. The Internet has become an essential part of our life. It cuts across geographical boundaries facilitating new opportunities, and learn new things faster. Today, the Internet has led to many disruptive innovations, disruptive business, and has grown in to one of the biggest economy in the world. Today, the Internet has become an integral part of everyday life especially among the teenagers.

Table 1 shows the world Internet usage statistics where, Asia tops the list in terms of highest number of Internet users with an Internet penetration rate of $48.1 \%$. Malaysia has an Internet penetration of $78.3 \%$ with $68.7 \%$ penetration in terms of Facebook subscribers as of 31 December 2017 [2]. This statistics shows that Malaysia is one of the countries in Asia with a very high Internet penetration rate and substantially high number of users active on social media.

\footnotetext{
* Corresponding author: rajakumar.murugesan@taylors.edu.my
} 
With the growing use of the Internet, excessive use of the Internet that could interfere daily routine activities may become a concern. The higher Internet penetration rate could positively influence the Internet overuse or addiction occurrence rate. This establishes a raising concern with especially youngsters. Studies from the University of Hong Kong done in December 2014 shows that the Internet addiction around the world is about $6 \%$ while, in Asia it is about $7.1 \%$ [3].

Table 1. World Internet usage statistics [1]

\begin{tabular}{|c|c|c|c|c|c|c|}
\hline \multicolumn{7}{|c|}{ WORLD INTERNET USAGE AND POPULATION STATISTICS } \\
DEC 31, 2017 - Update \\
\hline $\begin{array}{c}\text { World } \\
\text { Regions }\end{array}$ & $\begin{array}{c}\text { Population } \\
(2018 \text { Est.) }\end{array}$ & $\begin{array}{c}\text { Population } \\
\% \text { of } \\
\text { World }\end{array}$ & $\begin{array}{c}\text { Internet Users } \\
31 \text { Dec } 2017\end{array}$ & $\begin{array}{c}\text { Penetration } \\
\text { Rate } \% \\
\text { Pop.) }\end{array}$ & $\begin{array}{c}\text { Growth } \\
2000- \\
2018\end{array}$ & $\begin{array}{c}\text { Internet } \\
\text { Users } \\
\%\end{array}$ \\
\hline Africa & $1,287,914,329$ & $16.9 \%$ & $453,329,534$ & $35.2 \%$ & $9,941 \%$ & 10.9 \\
\hline Asia & $4,207,588,157$ & $55.1 \%$ & $2,023,630,194$ & $48.1 \%$ & $1,670 \%$ & 48.7 \\
\hline Europe & $827,650,849$ & $10.8 \%$ & $704,833,752$ & $85.2 \%$ & $570 \%$ & 17.0 \\
\hline $\begin{array}{c}\text { Latin } \\
\text { America }\end{array}$ & $652,047,996$ & $8.5 \%$ & $437,001,277$ & $67.0 \%$ & $2,318 \%$ & 10.5 \\
\hline $\begin{array}{c}\text { Middle } \\
\text { East }\end{array}$ & $254,438,981$ & $3.3 \%$ & $164,037,259$ & $64.5 \%$ & $4,893 \%$ & 3.9 \\
\hline $\begin{array}{c}\text { North } \\
\text { America }\end{array}$ & $363,844,662$ & $4.8 \%$ & $345,660,847$ & $95.0 \%$ & $219 \%$ & 8.3 \\
\hline $\begin{array}{c}\text { Oceania / } \\
\text { Australia }\end{array}$ & $41,273,454$ & $0.6 \%$ & $28,439,277$ & $68.9 \%$ & $273 \%$ & 0.7 \\
\hline $\begin{array}{c}\text { WORLD } \\
\text { TOTAL }\end{array}$ & $7,634,758,428$ & $100.0 \%$ & $4,156,932,140$ & $54.4 \%$ & $1,052 \%$ & 100 \\
\hline
\end{tabular}

Internet Addiction refers to the overuse of the Internet that affects a person's daily routine life. Internet addiction is the inability to control Internet use that leads to depression, anxiety and abnormal behaviour if deprived of Internet use. Internet Addiction Disorder (IAD) is described by Dr Ivan K Goldberg as the symptoms of giving up or reduced social or occupational activities because of the use of the Internet [4]. Internet with cheaper and fast bandwidth has made easy access especially now freely available in most restaurants. Repercussions and undesirable outcomes may happen due to negative selfperception among users with Internet addiction. This could lead to poor mental health, stress, low self-esteem, anxiety, depression, and loneliness that would affect the lifestyle of a person. The above reasons had motivated this study on Internet addiction among teenagers in Malaysia.

This main objectives of this study are; to investigate on the number of teenagers who have Internet dependency based on demographic characteristics, Internet usage, family and other related factors such as personal characteristics and psychology of an individual; Identify the type of internet addiction and the factors that influence this disorder among teenagers; and to develop a mitigation framework on the issues of Internet addiction.

This study was conducted with teenagers in the age of 13 to 17 years old studying in the schools located in Hulu Langat and Kajang in the state of Selangor in Malaysia. Reason being that Selangor is the state with highest Internet penetration rate in Malaysia. A sample size of 430 students was used. The next section of this paper reviews critically the existing 
literature on Internet addiction and assessment methods. Section 3 discusses the research method, Section 4 discusses the results and findings. Section 5 concludes the paper.

\section{Internet Addiction}

\subsection{Internet Addiction Disorder}

Excessive use of the Internet possibly for online relationships, socialising, chat rooms, gaming, gambling, shopping or browsing would result in Internet addiction. Internet addiction as a disorder was matured by Dr Young which used to be classified as pathological gambling [5]. Internet Addiction Disorder (IAD) is also synonymously called as Problematic Internet Use (PIU) [6], Internet dependence [7], and compulsive Internet use [8]. According to Beard [9], the following five criteria needs to be satisfied to be diagnosed as Internet Addiction: Internet preoccupancy, Need to use the Internet most of the time to get satisfaction, Efforts to manage, control, reduce or stop using the Internet were not successful, Gets restless, depressed, moody or irritated when trying to reduce or stop using the Internet. In addition to the above, he says that any one of the following three criteria must be met: Has risked losing an important relationship, Lies to the family or others excessive use or dependency of the Internet, and use the Internet to escape from problem or difficult situation.

\subsection{Internet Addiction Prevalence}

The Internet has become an integral part of our life and as essential as water and electricity. Today there are many people who quip that they cannot live without the Internet. A study on public attitude over using the Internet conducted by Ipsos across 23 countries involving about eighteen thousand people shows that two-third of the respondents cannot imagine life without the Internet. The top ten countries with Internet addiction prevalence was India $82 \%$, Great Britain $78 \%$, China $77 \%$, Germany $73 \%$, United States $73 \%$, Russia $66 \%$, Spain $65 \%$, France $64 \%$, Italy $62 \%$ and Japan $62 \%$ [10]. The same study also reveals the frequency of use of the Internet. The top ten countries that has highest frequency of use of the Internet are Canada 97\%, Great Britain 95\%, Russia 96\%, Sweden 96\%, Australia 96\%, Indonesia 95\%, Poland 95\%, S Korea 94\%, and U.S., Belgium, Germany and S Africa 94\% each. Most of these studies focused on younger population. From the above study it can be observed that the Internet addiction prevalence is more in Asian countries. It is observed that young age, early exposure to the Internet, frequent use, and environmental factors influences Internet addiction [11-13].

\subsection{Internet Addiction Assessment}

There are many instruments that have been developed for the Internet addiction assessment. The study done by Laconi et al on the measurement of Internet addiction identifies forty five such tools [14]. All these instruments measure Internet addiction through scales, interviews or diagnostics done through questionnaires. Among these, the Internet Addiction Test (IAT) [15], the Chen's Internet addiction scale (CIAS) [16], the Compulsive Internet Use Scale (CIUS) [17], and the Generalized Problematic Internet Use Scale (GPIUS) [18] were found to be most commonly used. Studies shows that IAT exhibits excellent test, retest reliability and excellent internal consistency of $r \geq 0.75$, and $a=0.92$ respectively [19-21]. 


\section{Research Methodology}

This study in terms of a theoretical framework tries to understand the Internet addiction among teenagers by studying the student's personal characteristics and their cyber behaviour. The key dimension used to conceptualize the concerns include losing control of time in online activity, escaping from social activities, and compulsive response to environment. As for students personal characteristics the key dimensions used are gender, self-esteem, adjusting to family, adapting to learning, and interpersonal relationship. For Cyber behaviours, the key dimensions are entertainment, social communication online, virtual emotions and browsing for information search.

The research conceptual framework for this study is developed based on the modification of IAT $[15,20]$. This conceptual framework to study the factors that influence Internet addiction tendency is shown in Fig. 1.

\begin{tabular}{|c|c|c|}
\hline $\begin{array}{l}\text { Demographic } \\
\text { Characteristics }\end{array}$ & $\begin{array}{l}\text { a. Gender } \\
\text { b. Age } \\
\text { c. Race }\end{array}$ & \\
\hline $\begin{array}{l}\text { Internet use- } \\
\text { related factors }\end{array}$ & $\begin{array}{l}\text { a. Motives use } \\
\text { b. Ease access } \\
\text { c. Popular Websites } \\
\text { d. Internet expectations }\end{array}$ & $\begin{array}{l}\text { Internet } \\
\text { Addiction } \\
\text { Tendency }\end{array}$ \\
\hline $\begin{array}{l}\text { Family \& other } \\
\text { agencies } \\
\text { related factors }\end{array}$ & $\begin{array}{l}\text { a. Parental control over Internet } \\
\text { use } \\
\text { b. Parent support } \\
\text { c. School support } \\
\text { d. Government support }\end{array}$ & \\
\hline $\begin{array}{l}\text { Personal \& } \\
\text { Psychology } \\
\text { factors }\end{array}$ & $\begin{array}{l}\text { a. Depression } \\
\text { b. Loneliness } \\
\text { c. Social Isolation } \\
\text { d. Self-control }\end{array}$ & \\
\hline & e. Inter-personnel relationship & \\
\hline
\end{tabular}

Fig. 1. Conceptual frameworks for internet addiction tendency.

Questionnaires were used to collect data from the teenagers. The questionnaire comprises of three sections, where the $1^{\text {st }}$ section had twenty questions to assess the level of Internet addiction from the frequency of Internet usage. $2^{\text {nd }}$ section had five questions to assess the type of Internet addiction, and $3^{\text {rd }}$ section had six questions. Out of 500 questionnaires distributed, 430 were received completed. The study was conducted in Kajang and Hulu Langat in the Selangor state of Malaysia. Four out of forty five schools were used for this study. 


\section{Results and Analysis}

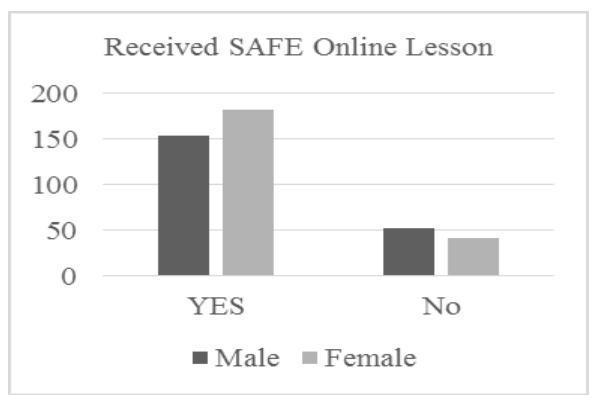

Fig. 2. Number of teenagers who received safe online lesson.

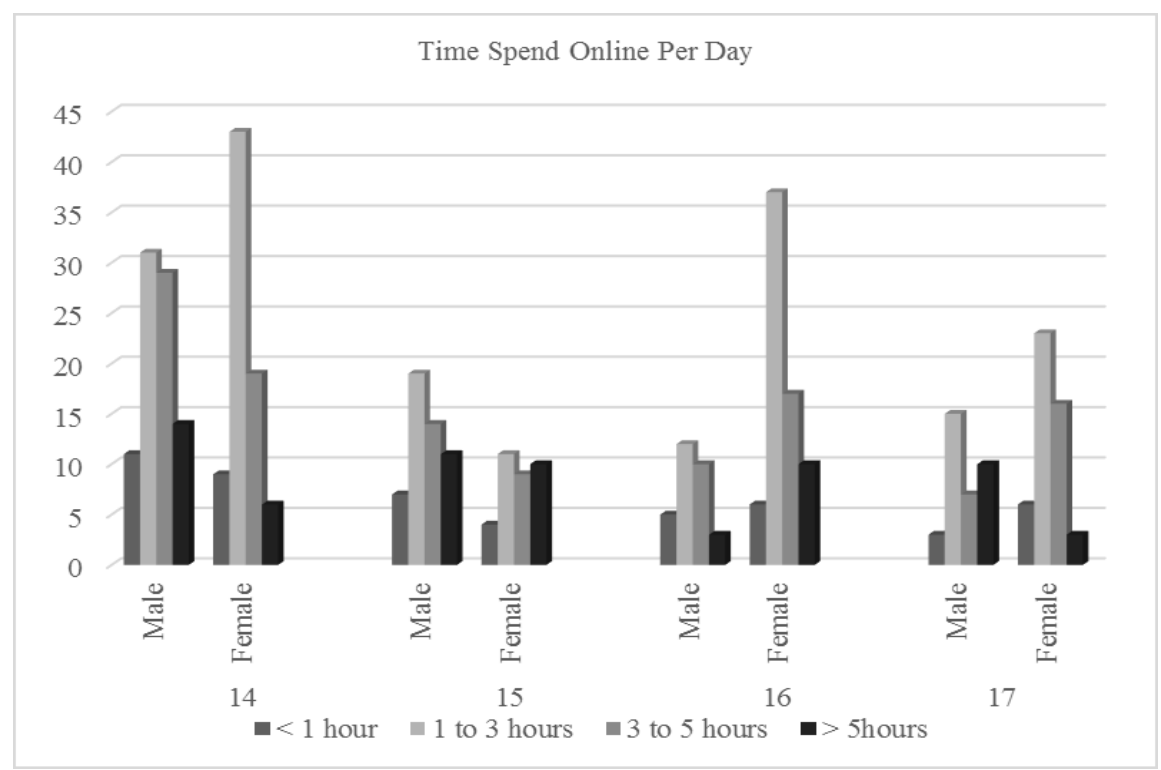

Fig. 3. Time spent online per day.

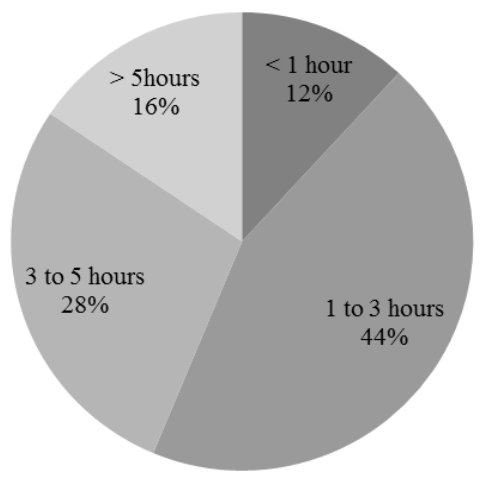

Fig. 4. Percentage of Time spent online per day. 
Among the respondents, $31.6 \%$ were in the age group of $14,30.7 \%$ were in the age group of 16, 21.86\% were in the age group of 17, and 16.28\% were in the age group of 15 . Some of the results obtained through the questionnaire is shown in Fig. 2 to 5.

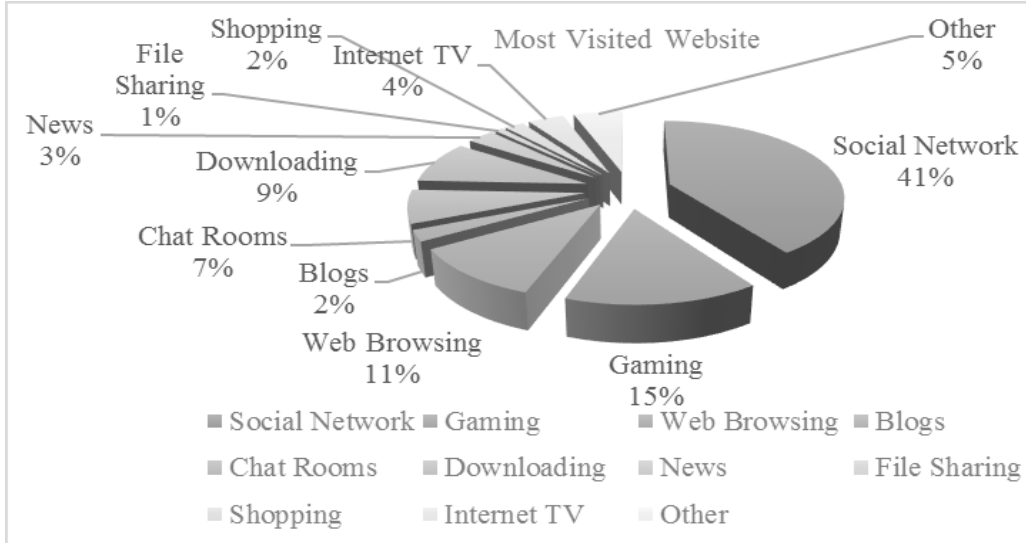

Fig. 5. Most visited website on a day.

From the data obtained for the time spend on Internet per day by teenagers in the age of 14 to 17 years old are that chi-square $=27.3$, degrees of freedom $=21$, and probability $=$ 0.161 . The probability of Internet addiction to happen is only 0.161 which, is minimal. The limitation of this research is that the data collected is only from four different schools in the state of Selangor and the conclusion made may not represent as a whole for the entire state of Selangor or Malaysia.

\section{Conclusion}

Increased and frequent use of the Internet could lead to Internet addiction that would be of major concern especially for adolescents or teenagers. This study was done to assess the level and type of Internet usage among Malaysian teenagers with the sample of data taken from four schools in the state of Selangor. IAT made and statistical analysis shows that the level of Internet addiction is minimal and is not of a concern. Though Internet Addiction is not observed to be a concern from the sample data taken it will be good to be aware of the level of Internet use periodically so that proper measures could be made in place to deter or mitigate Internet Addiction.

\section{References}

1. World Internet Usage and Population Statistics (Dec 312017 update).

2. Asia Marketing Research, Internet Usage, Population Statistics and Facebook Subscribers Dec. 31(2017)

3. Cecilia Cheng and Angel Yee-lam Li. Cyberpsychology, Behav., and Soc. Networking. 17, 12 (2014)

4. D. Wallis, Just Click No. The New Yorker January 13, 28 (1997)

5. K.S. Young, Internet addiction: The emergence of a new clinical disorder. 104th annual meeting of the American Psychological Association; (1996)

6. R. A. Davis, A cognitive behavioural model of pathological internet use (PIU) Comput. in Hum. Behav. 17(2), 187-95 (2001) 
7. N. A. Dowling and Quirk KL, Screening for Internet dependence: do the proposed diagnostic criteria differentiate normal from dependent Internet use? Cyberpsychol Behav. 12(1), 21-7 (2009)

8. S. E. Caplan, Problematic Internet use and psychosocial well-being: development of a theory-based cognitive-behavioural measurement instrument. Comput. in Hum. Behav. 18 (5), 553-75 (2002)

9. K. W. Internet addiction: a review of current assessment techniques and potential assessment questions. Cyberpsychol Behav. 8(1):7-14 2005

10. Life without the Internet. Technology - Attitudes and Use, Charts. Ipsos Global Trends. (07 Aug 2018)

11. D. J. Kuss, O. L. Lopez-Fernandez, Internet addiction and problematic Internet use: A systematic review of clinical research. World. J. Psychiatr 22 (6-1), 143-176 (2016)

12. E. Stip, A. Thibault, Beauchamp-Chatel Ab, et al. Internet addiction, hikikomori syndrome, and the prodromal phase of psychosis. Front. Psychiatry 7: 6 (2016)

13. S. Krishnamurthy, S. K. Chetlapalli, Internet addiction: prevalence and risk factors: a crosssectional study among college students in Bengaluru, the Silicon Valley of India. Ind. J. Public. Health 59 (2), 115-121 (2015)

14. S. Laconi, R. F. Rodgers \& Chabrol H: The measurement of Internet addiction: a critical review of existing scales and their psychometric properties. Comput. Hum. Behav. 41, 190-202 (2014)

15. K. S. Young, Internet Addiction: The Emergence of a New Clinical Disorder. CyberPsychology. Behav. 1, 237-244 (1998)

16. S. Chen, L. Weng L, Y. Su, H. Wu, and P. Yang, Development of a Chinese Internet addiction scale and its psychometric study. Chinese J Psychol. 45:279, (2003)

17. G. Meerkerk, RJJM. Van Den Eijnden, A. A. Vermulst, and H. F. L. Garretsen, The Compulsive Internet Use Scale (CIUS): some psychometric properties. Cyberpsychol Behav. 12, 1-6 (2009)

18. Caplan S: Problematic internet use and psychosocial well-being: Development of a theory-based cognitive behavioural measurement instrument. Comput. Hum. Behav. 18, 553-575 (2002)

19. A. Barke, N. Nyenhuis, and B. Kroner-Herwig, The German version of the internet addiction test: a validation study. Cyberpsychol Behav. Soc. Netw. 15, 534-542 (2012)

20. K. Lee, H. Gyeong, Yu B, Y. M. Song, H. K. Lee and D. Kim, Reliability and validity of the Korean version of the internet addiction test among college students. J Korean Med Sci. 28, 763-768 (2013)

21. H. Osada, Internet addiction in Japanese college students: Is Japanese version of Internet Addiction Test (JIAT) useful as a screening tool. Bull Senshu Univ Sch Hum Sci. 3, 71-80 (2013) 